\title{
Scale-up analysis and critical issues of an experimental pilot plant for edible film production using agricultural waste processing
}

\author{
Fabrizio Sarghini, Prospero Di Pierro, Antonio Veneruso, Paolo Masi \\ Department of Agriculture, University of Naples Federico II, Portici (NA), Italy
}

\begin{abstract}
This study was developed to test a multifunctional experimental pilot plant with a reduced environmental impact that is able to process agricultural (fennel) and food production (liquid whey) waste. The pilot plant, using different thermal and filtration process parameters, is able to recover pectin and whey proteins in a single processing unit in order to produce edible films. An innovative feature of the proposed configuration is related to the possibility of coupling different types of waste treatment, obtaining a final product with a higher economical value, combining the two processing lines. Although an edible film production procedure based on pectin extracted from fennel matrix and whey proteins has already been published in literature, the scale-up process highlighted several critical issues, in particular related to the fennel matrix. Nonetheless, the pilot plant configuration allowed an edible film to be produced that is suitable for use as a direct coating to improve the shelf-life of food products.
\end{abstract}

\section{Introduction}

Edible films and coatings can be considered a thin layer of edible material, pre-formed or formed directly on the food, which is used as a coating or inserted between the different components of the food itself (Krochta and De Mulder-Johnston, 1997).

Usually there are two main types of edible films: in the first, the coatings are already part of the food and can be present as natural components (e.g. the edible rind of the fruit); the second type is the result of technological processing and can be used directly on the sur-

Correspondence: Fabrizio Sarghini, Department of Agriculture, University of Naples Federico II, via Università 100, 80055 Portici (NA), Italy.

E-mail: sarghini@unina.it

Key words: fennel waste, whey, agricultural waste treatment, pectin, edible film, experimental pilot plant.

Received for publication: 19 September 2012.

Accepted for publication: 6 February 2013.

(C) Copyright F. Sarghini et al., 2012

Licensee PAGEPress, Italy

Journal of Agricultural Engineering 2012; XLIII:e22

doi:10.4081/jae.2012.e22

This article is distributed under the terms of the Creative Commons Attribution Noncommercial License (by-nc 3.0) which permits any noncommercial use, distribution, and reproduction in any medium, provided the original author(s) and source are credited. face of the product (e.g. the crust of the cheese which is formed by salting treatments and dehydrating the cheese surface). The films, however, can essentially be considered independently, obtained from a formulation separated from the food product itself.

Film may be applied directly to the food (e.g. the chocolate that covers ice cream cones, butter for frying food, etc.), or used as covers, pouches and as a separating layer.

The aim of an edible film and other biodegradable products is simple: replace the existing synthetic non-biodegradable film at the lowest possible cost, while still maintaining the same barrier properties.

Moreover, for edible types, another important target is to improve the quality and shelf-life of the food products, reducing the effect of moisture, of the oxidative processes, etc., while protecting the integrity of the food from microbial contamination and, finally, maintaining, and possibly improving, the visual aesthetic appeal of the product.

An important characteristic is the cost of the materials used and of the technological process applied for the coating. In the balance sheet analysis these costs must be evaluated in terms of the benefits in quality and shelf-life improvements.

Last but not least, if the resulting packaging is simpler, and at the same time is easier to recycle, it provides a further potential reduction in cost.

The possibilities for application of the edible films are based on: i) controlling the passage of water, the exchange of gas (oxygen, carbon dioxide and ethylene) and solutes, the diffusion and the absorption of oils and fats, the loss and the acquisition of aromas and volatile compounds; ii) including in its structure flavourings, antimicrobials, antioxidants, pigments and other additives; iii) improving the mechanical properties and easy handling.

Finally, films must be generally recognized as safe, organoleptically neutral, odourless, tasteless, clear and transparent, sufficiently stable in terms of their chemical, physical and microbiological properties, and easy to prepare and to use in the food industry. They must also have good mechanical properties (adhesion and cohesion) and a low economic impact on production. As the name suggests, an edible film must be prepared with edible materials so that it becomes an integral part of the food and can be ingested without any harm to the consumer.

Production of edible film can be obtained by post-processing agricultural and food industry wastes, the disposal of which represents a major environmental problem for the large amount of waste produced and for their elevated biological oxygen demand.

Several materials have been used to produce films, including polysaccharides like starch and starch derivatives, cellulose derivatives, alginates, carrageenan, chitosan, pectins and various rubbers. In addition, proteins can be combined with the polysaccharides to change the mechanical properties of the films (Shih, 1994; Arvanitoyannis et al., 1996, 1997, 1998a, 1998b; Arvanitoyannis and Biliaderis, 1998).

A possible source of raw materials for edible film production is represented by fennel and cheese production waste. The total amount of fennel waste estimated in Italy is $183 \times 10^{3}$ tons per year, equivalent to $40 \%$ of the 2012 Italian production (ISTAT, 2012). Cheese production generates $317 \times 10^{5}$ tons of liquid whey per year (ISTAT, 2011). 
In the economic framework, by-products are present in both wastes. In particular, fennel waste is rich in pectin while liquid whey contains a significant amount of proteins with an elevated biological value.

In this study, a combination of pectins obtained from fennel matrix [Foeniculum vulgare Mill. var. azoricum (Mill.) Thell.] (Giosafatto et al., 2007) and proteins recovered from buffalo milk whey waste were integrated into a protein network to produce an edible film, and a scaleup analysis of an experimental production pilot plant was performed.

\section{Materials and methods}

\section{Pilot plant description}

The scale-up process from laboratory to full-scale production often represents a critical issue, and some problems only present themselves when a full-scale test is performed. In order to develop and scale up a procedure for edible film production based on fennel waste, a multipurpose pilot plant was used. The plant is composed of a set of interconnected units and agitating tanks: i) six insulated tanks (S1-S6) for mixing and thermo-mechanical break up of agricultural and food waste matrices using variable speed rotating blades inserted into the tanks; ii) a refrigeration and a heating unit, with 3 modular plate heat exchangers; iii) mechanical standard filtration units (3 different filtration units connected to the S1-S2-S3 reservoirs: a twin $100 \mu$ metallic grid filter, and 2 polymeric variable size Millipore Polygard ${ }^{\circledR}$-CR filtration cartridges); iv) an ultrafiltration and concentration unit (Millipore ultrafiltration unit with Millipore Pellicon ${ }^{\circledR}$ cartridges); v) an external centrifugation unit. All units are served by 5 peristaltic variable size pumps with controlled rpm, with the possibility of reversing flow direction and to move products from any tank to that chosen, while temperature are digitally controlled on the control console. All quantities involved in the process were weighed with an electronic scale (Figure 1).

\section{Pectin extraction process}

Fennel cultivar was chosen due to the enormous quantities of agricultural waste from transformation residual (Italy is one of the world's main producers) and for the relevant pectin concentration in the fennel matrix. Pectin extraction and concentration processes are described in Figure 2. Tap water at $\mathrm{pH}=7$ was used, and warmed up to $80^{\circ} \mathrm{C}$ in order to deactivate pectin degradation enzymes. Once the temperature was set, the fennel matrix was inserted into the $\mathrm{S} 1$ reservoir, where the rotating blades provide the mechanical cutting action coupled with the thermal degradation of the matrix. After several filtration and ultrafiltration steps, the concentrated pectins are stored at low temperature in a separate jacketed tank. The method according to Dubois (Dubois et al., 1955) was used to evaluate the composition of polysaccharides and methylated derivatives. The method is based on the property of simple sugars, oligosaccharides, polysaccharides and their derivatives, including methyl esters, which have free or potentially free reducing groups, to give a yellow-orange colour when they are treated with phenol and concentrated sulphuric acid. The reaction is sensitive and the colour is stable.

\section{Protein concentration}

The second purpose of this type of experimental set up was to investigate the possibility of applying the same mechanical configuration to extract proteins from dairy waste using membrane technology (Pouliot et al., 1999, Cheang and Zydneyb, 2004), further reducing investment costs. A coarse filtration was performed by using the first two filters, aimed at eliminating the presence of excessively voluminous solids, such as caseinates, which may lead to fouling problems. The protein concentration process is described in Figure 3.
After passing through the $25 \mu \mathrm{m}$ filter, the filtered whey reaches the reservoir S4 ready to undergo the process of ultrafiltration, where the membrane ultrafiltration unit had a cut-off size (molecular cut) of $10 \mathrm{kDa}$. Starting from a batch of $30 \mathrm{~kg}$ of dairy whey waste of buffalo milk, used for mozzarella cheese production, after 90-min ultrafiltration, $27 \mathrm{~kg}$ were discharged in the permeate.

\section{Edible film oxygen transmission rate evaluation}

The oxygen transmission rate (OTR) in the edible film was determined using a modification of the ASTM standard method D 3985-81 (ASTM, 1990) using a self-assembled laboratory permeabilimeter at $25^{\circ} \mathrm{C}$. The oxygen permeability $\left(\mathrm{PO}_{2}\right)$ was calculated from the following equation:

$$
\mathrm{PO}_{2}=\frac{0 \mathrm{TR} \times \delta}{\Delta \rho}
$$

where:

$\mathrm{PO}_{2}$ is the oxygen permeability $\left(\mathrm{cm}^{3} \mu \mathrm{m}^{-2} \mathrm{kPa}^{-1}\right)$;

OTR is the oxygen transmission rate $\left(\mathrm{mL} \mathrm{m}^{-2}\right.$ day);

$\delta$ is the thickness $(\mathrm{m})$;

$\Delta \rho$ is the difference in partial pressure between the two sides of the film $(\mathrm{kPa})$.

The difference in pressure across the film corresponds to the atmospheric pressure $(101.3 \mathrm{kPa})$, the film samples being subjected to $100 \%$ oxygen gas on one side and a stripping gas containing $98 \%$ nitrogen and $2 \%$ hydrogen on the other.

The analyses were carried out in duplicate with the films conditioned at a temperature of $25^{\circ} \mathrm{C}$ and $52 \% \mathrm{RH}$ for $48 \mathrm{~h}$.

\section{Results}

\section{Pectin extraction and concentration}

In order to set up an optimal extraction protocol, thermo-mechanical process parameters (extraction time and temperature) were investigated, together with fennel matrix-water dilution ratio.

The thermo-mechanical degradation process of fennel waste, without any preliminary cleaning treatment, showed that the first problem is linked to the presence of green leaves that tend to interact with the rotating blade, building a capsule around it and strongly reducing its cutting capacity, so that a mechanical pre-processing cleaning phase

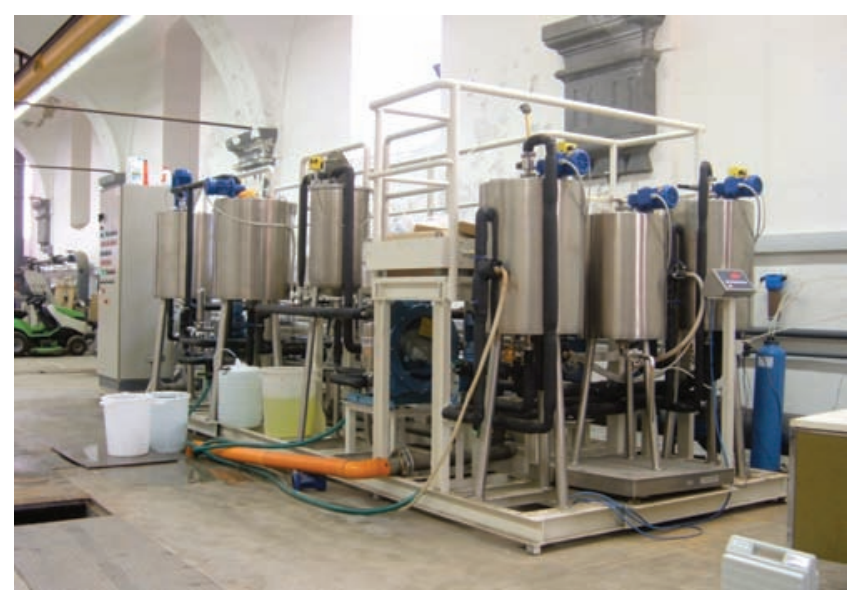

Figure 1. The experimental pilot plant. 
was required. In order to separate pectins from proto-pectins in agricultural product with a thick epicarp, such as in Citrus or in tomato skin, an acid treatment is usually required. In our case, the possibility of using a simple thermo-mechanical extraction with a neutral $\mathrm{pH}$ was the main object of our investigation in order to avoid the possibility of protein precipitation due to the presence of a low $\mathrm{pH}$ solution.

In fact, pectins in fennel matrix are mechanically structured and their relatively soft cellular membrane mean that theoretically they can be extracted without using any acid solutions.

Commercial pectins were used as a reference with a concentration of $15 \mu \mathrm{g} / \mu \mathrm{L}$.
In Figure 4, the extraction yield of pectins versus time is reported for two different mass dilution ratios (fennel $\mathrm{kg} /$ water $\mathrm{kg}$, yellow=1/5, blue $=1 / 10$ ).

In the first dilution experiments, $10 \mathrm{~kg}$ of fennel waste versus $50 \mathrm{~kg}$ of water were used, and the solution was sampled during $5 \mathrm{~h}$ of thermo-mechanical treatment.

Results show that after $1 \mathrm{~h}$ the extraction process has mostly been completed, and that the final yield does not depend to any great extent on the dilution ratio, at least in the range considered.

A further reduction in the initial ratio would result in a more dense solution at the exit of the trituration tank. This could increase problems

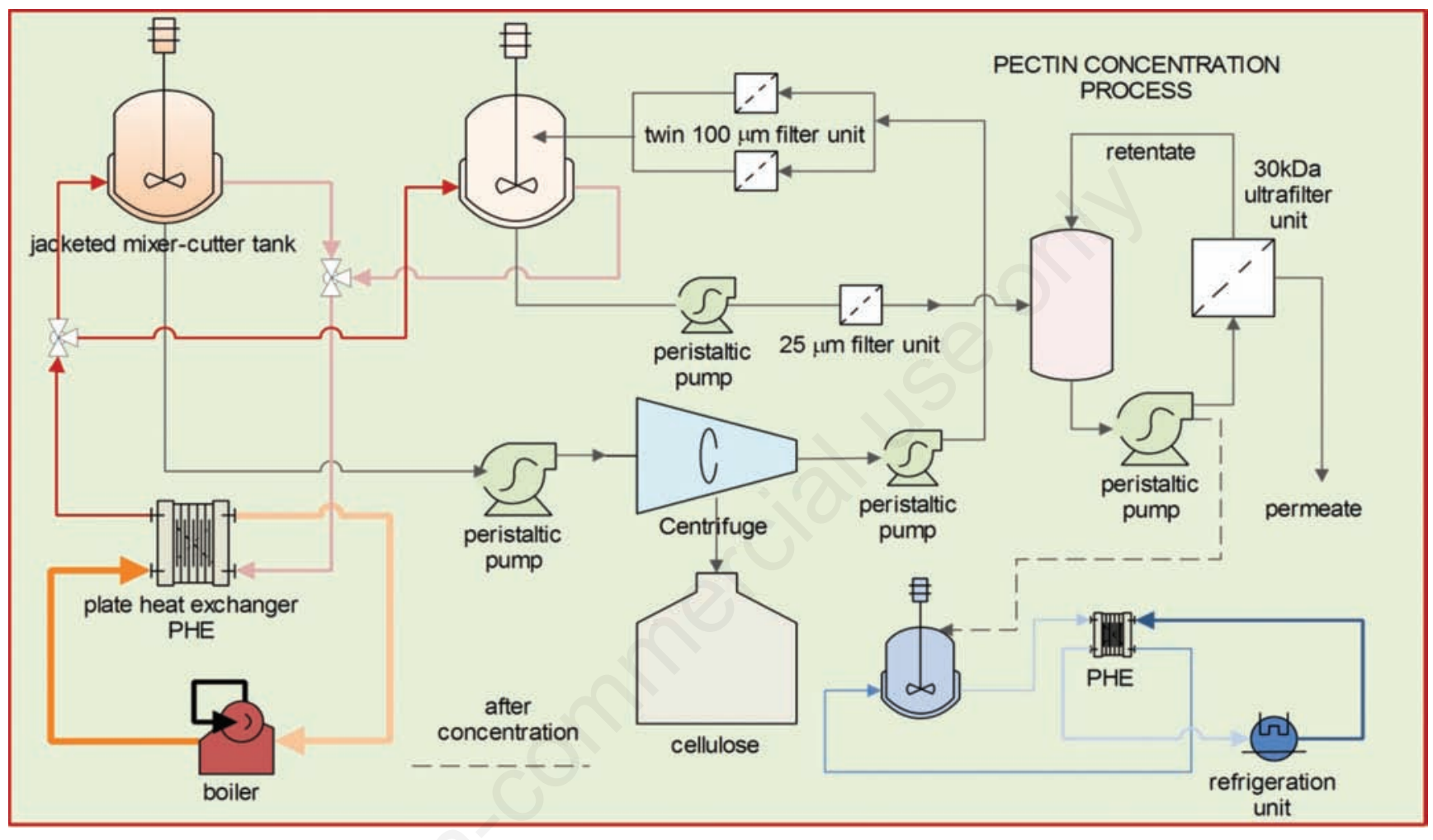

Figure 2. Pectin extraction and concentration process.

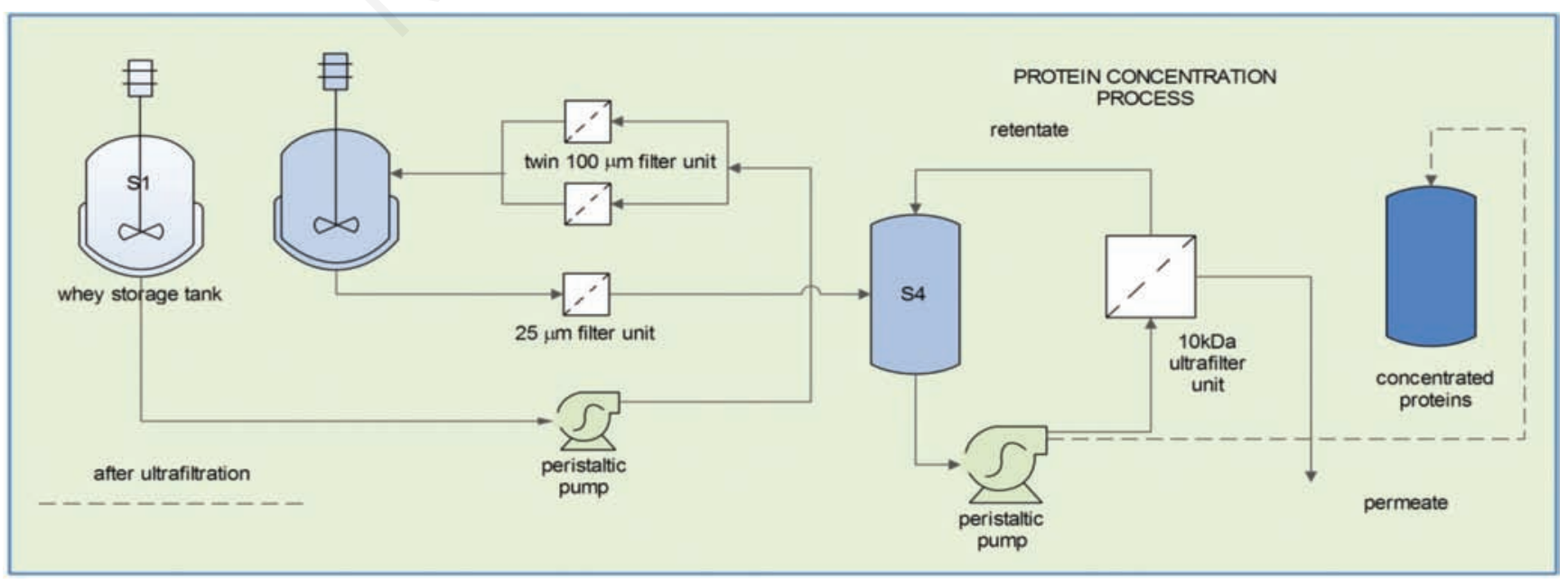

Figure 3. Protein concentration process. 
related to infiltration in order to obtain a clean solution before reaching the ultrafiltration unit for the final stage of pectin concentration.

One of the problems that was immediately evident in the pilot plant was the effect of the presence of a strong cellulose component in the fennel-water solution after thermo-mechanical maceration (Figure 5).

In fact, the twin $100 \mu \mathrm{m}$ metallic cartridge filter was not sufficient to clean the solution from this component. A filter cake was formed, with a resultant lower cut-off size, and a reduction in pectin entrapment in the cake before reaching the ultrafiltration unit.

Interestingly, there was a reduction in pectin concentration after $5 \mathrm{~h}$ of thermo-mechanical treatment. This could be a consequence of chemical degradation linked to an enzymatic process of endogen deesterification, precipitation due to the presence of $\mathrm{Ca}^{2+}$ in water, or elimination due to high temperature (Kenner, 1955) (Figure 4). In order to reduce $\mathrm{Ca}^{2+}$ concentration, a water column treatment unit was then included in the pilot plant.

\section{Protein concentration}

Protein concentration was evaluated by using the Bradford essay method (Bradford, 1976; Stoscheck, 1990); results are shown in Table 1 where $S_{1}$ is the dairy whey at the initial protein concentration, $S_{2}$ after $100 \mu \mathrm{m}$ filtration, $S_{3}$ after $25 \mu \mathrm{m}$ filtration, $P$ is the permeate, and $R_{1}$ is the solution in the ultrafiltration tank at time $t=0, R_{2}$ at the end of the filtering process.

\section{Edible film production}

The production of biodegradable and edible films with the desired mechanical characteristics and gas barrier properties represents one of the most advanced challenges in the field of food wrapping and coating. Polymers derived from natural products such as carbohydrates and proteins offer interesting opportunities when used as a component of edible films for their biodegradability and environmental compatibility. However, excessive water solubility and poor water vapour barrier properties, and the often poor mechanical resistance, have meant that their application has so far been limited.

In our study, the edible film was obtained by crosslinking as a structuring adjuvant the enzyme transglutaminase with pectin and proteins, to create an environmentally-friendly bioplastic with mechanical and permeability properties possibly similar to those exhibited by plastics of petrochemical origin (Porta et al., 2011).

There was a clear ultrafiltration effect (Figure 6). The first two films (Figure 6A and $\mathrm{B}$ ) were cast by using pectins sampled after the thermo-mechanical treatment (before filtration), while the third (Figure 6C) was obtained using concentrated and purified pectins after ultrafiltration.

Since the main purpose of this study was to study the scale-up properties and problems of the experimental pilot plant with respect to the laboratory process, details of all film permeability and mechanical tests are not provided, apart from oxygen permeability.

The calculated $\mathrm{PO}_{2}$ index was equal to 5.13; a relatively high value if compared with high-density polyethylene (0.3) or low-density polyethylene (2.2).

\section{Conclusions}

The application of the data published in the literature, almost all coming from laboratory experiments, in this technological industrialscale edible film production process is not entirely linear. In some cases, the real working conditions seem to diverge greatly from laboratory data, and in some cases need to be adapted.

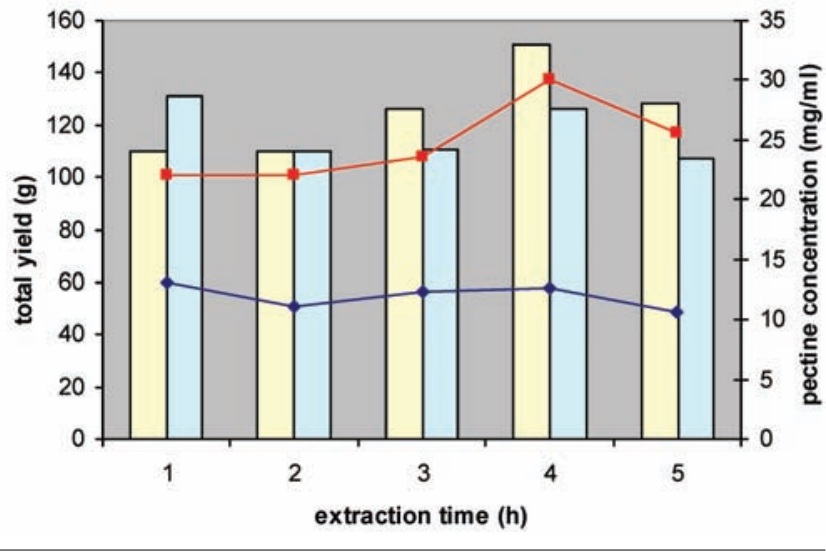

Figure 4. Extraction time for fennel $\mathrm{kg} /$ water $\mathrm{kg}$ ratio: yellow $=1 / 5$, blue $=1 / 10$.

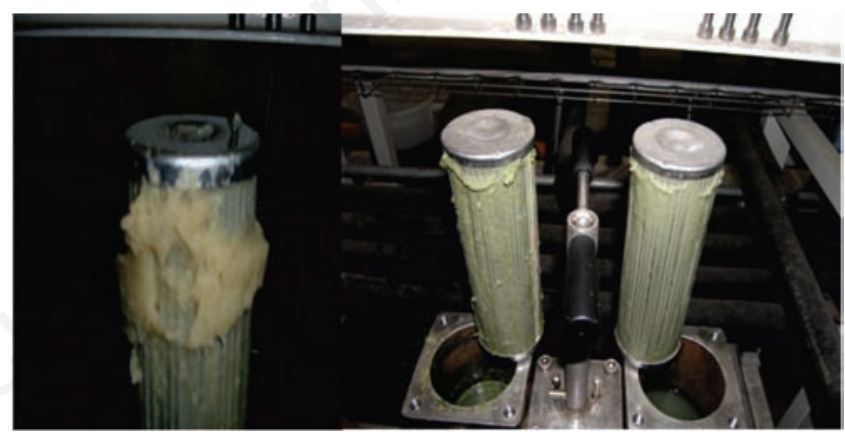

Figure 5. Cellulose cake formation in the twin $100 \mu \mathrm{m}$ filters.
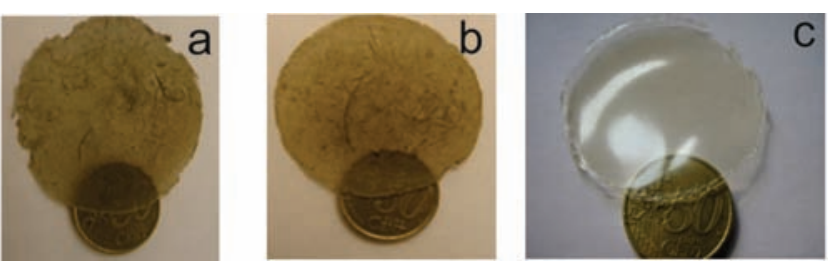

Figure 6. Edible film obtained by casting.

Table 1. Protein concentration after ultrafiltration.

\begin{tabular}{cc}
$\begin{array}{c}\text { Proteic concentration after ultrafiltration } \\
\text { Sample }\end{array}$ & g/Lin-max) \\
$\mathrm{S}_{1}$ & $0.804-1.54$ \\
$\mathrm{~S}_{2}$ & $1.11-1.4$ \\
$\mathrm{~S}_{3}$ & $1.05-1.4$ \\
$\mathrm{P}$ & $0-0.06$ \\
\hline $\mathrm{R}_{1}$ & $0.90-0.96$ \\
$\mathrm{R}_{2}$ & $5.2-5.6$ \\
\hline
\end{tabular}


For example, the parameters cannot be easily controlled since they are obtained in small experimental systems. The large masses of fennel waste used in an industrial plant require long processing times and the coarse exposure allows multiple agents to interfere with the production yield.

The analysis of the working conditions of this experimental plant showed several issues to be addressed compared to the laboratory process. The first is specifically related to the product used as a matrix. The starting fennel substrate in the process is a large nonhomogeneous fennel mass in which the conditions of maturation can be rather heterogeneous, not only varying from one experiment to another, but also within the same batch. This is important because the higher the degree of maturation, the higher the action of pectin degradation by already active enzymes, to the extent that an excessive maturation would give very low yield both in terms of molecular weights and esterification grade. In addition, there are differences related to the seasonality of the product. Although fennel is available on the market throughout the year, cultivars may differ in the amount of pectin contents and grade.

The second issue is related to the extraction process itself. Here, the first problem is related to the dilution ratio between fennel waste and water in the pectin extraction process. This needs to be maintained close to a ratio of 1 to 10 in order to avoid overpressure in the peristaltic pumps. The time length and the temperatures used in this process involve a large amount of energy to obtain a significant amount of product. A second problem is related to the filtration process, in particular to the filter cake formation in the $100 \mu \mathrm{m}$ twin filter unit. The fibrous material, thickening on the walls of the unit, increases the filtration power of the sifting cartridge well beyond the $100 \mu \mathrm{m}$, and a large amount of pectin is lost. Even alternating use between the two cartridges does not solve this problem. Moreover, resuspending and centrifuging the residue of the filtering operation still resulted in an average $55 \mathrm{mg} / \mathrm{mL}$ of pectin.

During the filtering process there are not only quantitative but also qualitative losses: in the subsequent ultrafiltration phase, at the end of the process we obtained a sample of concentrated retentate which has $6 \mathrm{mg} / \mathrm{mL}$ of pectin and a permeate, to be discharged, with the same concentration.

Therefore, the pectins obtained before ultrafiltration have on average a low molecular weight (below $30 \mathrm{kDa}$ ), and they are equally divided between the two flows of the membrane. This was confirmed by a test carried out with standard pectin of molecular weight over $30 \mathrm{kDa}$ that, solubilized in known concentration, was always found only in the retentate by means of the analytical determination.

The process of protein concentration is more linear, although there are fouling issues to be dealt with and probably on a full-scale plant ceramic tubular membranes are more appropriate.

Although an edible film was obtained, its characteristics are still far from plastic polymeric films used in food industry, suggesting a possible use as a coating directly sprayed on the product to increase the shell-life rather than as a real polymeric film substitute. A specific study is required to establish the economic benefits of the process and compare the costs of a correct waste disposal process with production costs and the market value of the obtained film.

\section{References}

Arvanitoyannis I., Biliaderis C.G. 1998. Physical properties of polyolplasticized edible films made from sodium caseinate and soluble starch blends. Food Chem. 62:333-42.

Arvanitoyannis I.S., Nakayama A., Aiba S. 1998a. Chitosan and gelatin based edible films: state diagrams, mechanical and permeation properties. Carbohydrate Polym. 37:371-82.

Arvanitoyannis I., Nakayama A., Aiba S. 1998b. Edible films made from hydroxypropyl starch and gelatin and plasticized by polyols and water. Carbohydrate Polym. 36:105-19.

Arvanitoyannis I., Psomiadou E., Nakayama A. 1996. Edible films made from sodium caseinate, starches, sugars or glycerol, Part 1. Carbohydrate Polym. 31:179-92.

Arvanitoyannis I., Psomiadou E., Nakayama A., Aiba S., Yamamoto N. 1997. Edible films made from gelatin, soluble starch and polyols, Part 3. Food Chem. 60:593-604.

ASTM (American Society for Testing and Materials). 1990. Standart test methods for oxygen transmission rate through dry packages using a coulometric sensor, designation D 3985-81. ASTM, Philadelphia, PA, USA, pp 1177-1182.

Bradford MM. 1976. A rapid and sensitive for the quantitation of microgram quantitites of protein utilizing the principle of protein-dye binding. Anal. Biochem. 72:248-54.

Cheang B, Zydneyb AL. 2004. A two-stage ultrafiltration process for fractionation of whey protein isolate. J. Membrane Sci. 231:159-67.

DuBois M., Gilles K.A., Hamilton J.K., Rebers P.A., Smith F. 1956. Colorimetric method for determination of sugars and related substances. Anal. Chem. 28:350-6.

Giosafatto C., Mariniello L., Ring S., 2007. Extraction and characterization of foeniculum vulgare pectins and their use for preparing biopolymer films in the presence of phaseolin protein. J. Agric. Food Chem. 55:1237-40.

ISTAT (Italian Institute of Statistics). 2011. Raw materials and products produced by the dairy industry in Italy, Table L05. Available from: http://agri.istat.it

ISTAT (Italian Institute of Statistics). 2012. Fennel production in Italy, Table C10. Available from: http://agri.istat.it

Kenner J. 1955. The alkaline degradation of carbonyl oxycelluloses and the significance of saccharinic acids for the chemistry of carbohydrates. Chem. Ind. 727-30.

Krochta J.M., De Mulder-Johnston C. 1997. Edible and biodegradable polymer films: challenges and opportunities. Food Technol. 51:61-74.

Porta R, Mariniello L, Di Pierro P, Sorrentino A, Giosafatto CV. 2011. Transglutaminase cross-linked pectin- and chitosan-based edible films: a review. Crit. Rev. Food Sci. Nutr. 51:223-38.

Pouliot Y., Wijers M.C., Gauthier S.F., Nadeau L. 1999. Fractionation of whey protein hydrolysates using charged UF/NF membranes. J. Membrane Sci. 158:105-14.

Shih F.F. 1994. Interaction of soy isolate with polysaccharide and its effect on film properties. JAOCS. 71:1281-5.

Stoscheck, CM. 1990. Quantitation of protein. Methods Enzymol. 182:50-69. 